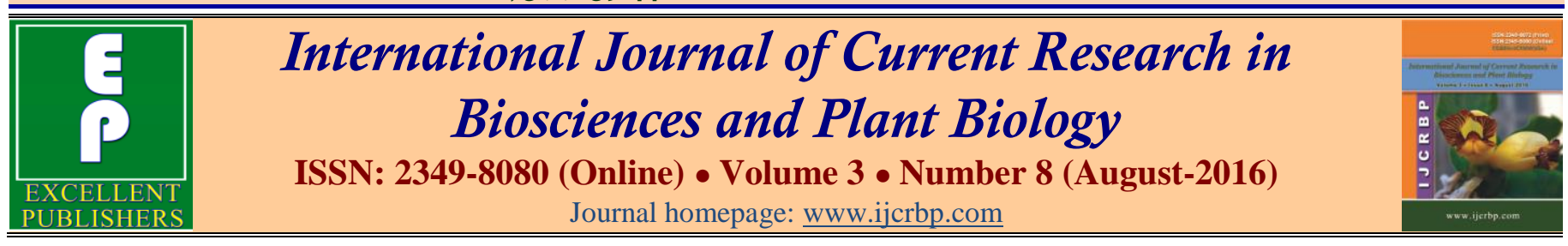

\title{
Antioxidant Activities and Phytochemical Analysis of Eclipta prostrata
}

\author{
A. D. Naveen Kumar ${ }^{*}$, M. Rama Devi², T. Kasi Naidu² and M.V.S. Mahesh Kumar3 \\ ${ }^{1}$ Department of Biomedical Sciences, College of Medical and Health Sciences, Adigrat University, Ethiopia \\ ${ }^{2}$ Department of Biomedical Sciences, Dilla University, Dilla, Ethiopia \\ 3 Sri Venkateswara College of Pharmacy, Srikakulam, Andhra Pradesh, India
}

*Corresponding author.

\begin{abstract}
A b stract
The objective of this study was to determine the antioxidant activities and phytochemical analysis of Eclipta prostrata. The present study was focused to evaluate the antioxidant and phytochemical analysis of various solvent extracts of Eclipta prostrata leaves by most accepted methods such as determination of DPPH radical scavenging activity, total antioxidant activity, superoxide radical scavenging activity, hydroxyl radical scavenging activity and Preliminary phytochemical analysis. The results showed that the methanolic extract exhibited significant DPPH, superoxide and hydroxyl radical scavenging activities. In addition, the methanolic extract also showed high total antioxidant activity. The present investigation provides scientific and folkloric use of Eclipta prostrata as an antioxidant agent.
\end{abstract}

\section{Article Info}

Accepted: 09 July 2016

Available Online: 06 August 2016

\section{Ke ywords}

Eclipta prostrata

Oxidative stress

Phytochemicals

Radical scavenging

\section{Introduction}

Over the centuries, plants have been considered the major sources of traditional medicines across the world. India is considered as a vast source of valuable medicinal and aromatic plant species that are used to treat various diseases and disorders in traditional system of medicine. In India, over 3000 plant species have been identified and reported to have medicinal properties, particularly antioxidants derived from medicinal plants have been used in the prevention and treatment of oxidative stress related diseases (Mazid et al., 2012). In the recent years, oxidative stress has been identified as one of the major reason for health hazards. Oxidative stress, excess generation of Reactive Oxygen Species (ROS), is a common event in the many pathological conditions such as Alzheimer's disease, neural disorders, cardiovascular diseases, Parkinson's disease, atherosclerosis, ulcerative colitis, several cancers and ageing including cancer (Md. Nur et al., 2013). The generation of reactive oxygen species (ROS) is an inevitable aspect of life under aerobic conditions. ROS are continuously produced as by products of certain metabolic pathways and also by some specific systems under fine cellular control. At the same time, ROS are degraded via several specific and nonspecific mechanisms. These two processes, i.e., generation and degradation of ROS, are usually under tight cellular control and very low $\left(<10^{-8} \mathrm{M}\right)$ steady-state levels are maintained (Halliwell and Gutteridge, 1989).

The medicinal plants are extensively utilized throughout the world in two distinct areas of health management, traditional and modern systems of medicine. The traditional system of medicine mainly functions through local or folk or tribal medicine. Medicinal plants contain an innumerable number of bioactive constituents with antioxidant activity including flavonoids and phenols (Packer et al., 1999; Latha and Daniel, 2001). Antioxidants are scavengers of free radicals and modifiers of various enzymatic functions. These antioxidant enzymes inhibit the generation of ROS either by removing potential oxidants or by transforming ROS 
into relatively stable compounds (Evans and Halliwell, 2001). The uses of medicinal plants as traditional medicine is wide spread and represent a large source of natural anti-oxidants that might serve as leads for the development of the novel drugs (Farnsworth and Soejarto, 1991). Recently, much attention has been directed towards the development of ethno-medicines with strong antioxidant properties (Maxwell, 1995).

Eclipta prostrata is small herb belongs to Asteraceae family and widely distributed in tropical and subtropical regions. It is used in the treatment of infective hepatitis in India (Wagner et al., 1986) and snake venom poisoning in Brazil (Melo et al., 1994). It was reported that the leaves of this herb are used to treat gastritis and respiratory disorders like cough and asthma (Kobari et al., 2004). The crude extracts of leaves are reported to have anti-inflammatory, antifungal and antihepatotoxic properties (Wong et al., 1988). But the antioxidant properties of the leaves of Eclipta prostrata are not completely evaluated.

The present study was focused to evaluate the antioxidant activities and phytochemical analysis of various solvent extracts of Eclipta prostrata leaves.

\section{Materials and methods}

\section{Chemicals}

1, 1-Diphenyl-2-picryl hydrazyl (DPPH), 2Thiobarbituric acid (TBA), Nitroblue tetrazolium chloride (NBT), Trichloroacetic acid (TCA), 2, 4, 6-tri(2-pyridyl)-s-triazine (TPTZ) were purchased from Sigma Chemicals Co. USA. All chemicals and solvents used in the present study were of the analytical grade.

\section{Collection and preparation of plant extracts}

The plant leaves were collected from the Eastern Ghats of Vizianagaram region and authenticated by the faculty in the Department of Botany, Andhra University, Visakhapatnam. The leaves were thoroughly cleaned, shade dried and powdered in a mechanical grinder. The powder was extracted with Soxhlet extractor using nhexane, chloroform, ethyl acetate and methanol for 72 hrs. The extracts were concentrated to dryness in desiccator. The solvent extracts were used to determine the DPPH radical scavenging ability and total antioxidant activity. Further, different concentrations of methanolic extract $(25,50,100,250,500,750$ and $1000 \mu \mathrm{g})$ were prepared in aforesaid solvents and were used to assay antioxidant, free radical scavenging and phytochemical analysis.

\section{DPPH radical scavenging activity}

DPPH scavenging activity was measured by the method of Cuendet et al. (1997). To $3.0 \mathrm{ml}$ of methanolic solution of DPPH $(0.1 \mathrm{mM}), 1.0 \mathrm{ml}$ of extract was added. In control, the extract was replaced by respective solvent. The reaction mixture was incubated for $30 \mathrm{~min}$ at $37^{\circ} \mathrm{C}$ and absorbance was measured at $517 \mathrm{~nm}$ using UVvisible spectrophotometer. The percentage of inhibition was calculated from the following equation: A0$\mathrm{A} \times 100 / \mathrm{A} 0$, where $\mathrm{A} 0$ and $\mathrm{A}$ are the absorbance of control and test sample, respectively. BHT and Quercetin were used as standards.

\section{Determination of total antioxidant activity}

The total antioxidant status was assayed by using FRAP method as described Wong et al. (2006) with some modifications. Briefly, $0.2 \mathrm{ml}$ of different concentrations $(25,50,100,250,500,750$ and $1000 \mu \mathrm{g} / \mathrm{ml})$ of solvent extracts were added to $3.0 \mathrm{ml}$ of FRAP reagent (mixture of $300 \mathrm{mM}$ sodium acetate buffer $(\mathrm{pH} 3.6), 10 \mathrm{mM}$, TPTZ solution and $20 \mathrm{mM} \mathrm{FeCl}_{3}$ in a ratio of 10:1:1. The reaction mixture was incubated in a water bath at $37^{\circ} \mathrm{C}$ for $30 \mathrm{~min}$. The increase in the absorbance was measured using spectrophotometer at $593 \mathrm{~nm}$. The total antioxidant capacity was assessed based on the ability to reduce ferric ions by the extracts. The percent of total antioxidant activity was calculated using a formula,

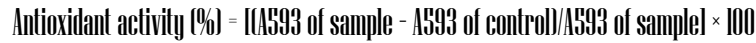

\section{Determination of Superoxide radical scavenging activity}

The superoxide radical scavenging ability was determined by the method of Beauchamp and Fridovich (1971). To $0.5 \mathrm{ml}$ of extract, $1.0 \mathrm{ml}$ of $0.12 \mathrm{M}$ sodium carbonate, $0.4 \mathrm{ml}$ of $25 \mu \mathrm{M}$ NBT and $0.2 \mathrm{ml}$ of $0.1 \mathrm{mM}$ EDTA were added. The reaction was initiated by adding $0.4 \mathrm{ml}$ of $1.0 \mathrm{mM}$ hydroxylamine hydrochloride and incubated for $20 \mathrm{~min}$. The absorbance was measured at $560 \mathrm{~nm}$ using spectrophotometer. The super oxide anion scavenging activity is calculated as percent inhibition of absorbance compared to the control.

\section{Determination of hydroxyl radical scavenging activity}

Hydroxyl radical scavenging activity was carried out by 
measuring the competition between deoxyribose and the extract for hydroxyl radical's generated by fenton reaction, a method originally described by Vardar-Unlü et al. (2003). $0.1 \mathrm{ml}$ of plant extract was added to the reaction mixture containing $0.1 \mathrm{ml}$ of $3.0 \mathrm{mM}$ deoxyribose, $0.5 \mathrm{ml}$ of $0.1 \mathrm{~m} \mathrm{M} \mathrm{FeCl} 3,0.5 \mathrm{ml}$ of $1 \mathrm{mM}$ $\mathrm{H} 2 \mathrm{O} 2$ and $0.8 \mathrm{ml}$ of $20 \mathrm{mM}$ phosphate buffer, $\mathrm{pH} 7.4$ in a final volume of $3.0 \mathrm{ml}$ and incubated at $37^{\circ} \mathrm{C}$ for $1 \mathrm{hr}$. The thiobarbituric acid reactive substances (TBARS) formed were measured by treating with $1.0 \mathrm{ml}$ of TBA $(1.0 \%)$ and $1.0 \mathrm{ml}$ of TCA $(2.8 \%)$ at $100^{\circ} \mathrm{C}$ for $20 \mathrm{~min}$. After the mixtures were cooled, absorbance was measured at $532 \mathrm{~nm}$ against control, which is devoid of plant extract. Percentage of inhibition was calculated as:

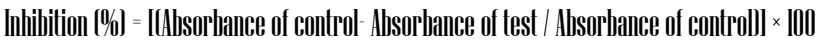

\section{Preliminary phytochemical analysis}

Phyto-chemical analysis of various solvent extracts was carried out to detect the presence of different phyto constituents by using standard qualitative tests (Sazada et al., 2009).

\section{Statistical analysis}

Each experiment was carried out three times separately. Data was expressed as mean $\pm \mathrm{SE}$ of minimum of six independent experiments. Statistical differences between control and target groups for all experiments were determined using Student's $t$-test. The statistical significance was determined at $5 \%(p<0.05)$ level. $\mathrm{IC}_{50}$ values are calculated at $90 \%$ confidence interval using regression analysis.

\section{Results and discussion}

Reactive oxygen species (ROS) are produced continuously in most tissues and are inextricably linked to malignant diseases, diabetes, atherosclerosis, chronic inflammation and ischemia-reperfusion injury (Droge, 2005). Epidemiological and in vitro studies have revealed that medicinal plant extracts protects biological systems from oxidative stress (Chaudhary et al., 2004). Eclipta prostrata is a well known medicinal plant and traditionally used for the treatment of stress mediated disorders. In the present study, total antioxidant and antiradical activities were used to determine antioxidant capacity of leafs extract of Eclipta prostrata is due to its differential mechanisms of antioxidant action. Oxygen derived radicals represent the most important class of radical species generated in living systems (Miller et al.,
1990). The harmful effect of free radicals causing potential biological damage is oxidative stress (Ridnour et al., 2005). DPPH, is a stable and non-physiological radical widely used for screening antioxidant activity of plant extracts. DPPH is reduced to diphenylpicryl hydrazine with plant extracts in a concentrationdependent manner (Nanjo et al., 1996). The radical scavenging ability of different solvent extracts on DPPH radical is in the following order: methanol> ethyl acetate $>$ chloroform >hexane with $82.50,62.17,43.65$ and $18.30 \%$, respectively, at $1000 \mu \mathrm{g} / \mathrm{ml}$ concentration (Fig. 1). Ascorbic acid represented the standard showed $85 \%$ total antioxidant activity at $1000 \mu \mathrm{g} / \mathrm{ml}$. Among these methanolic extract exhibited highest DPPH radical scavenging activity.

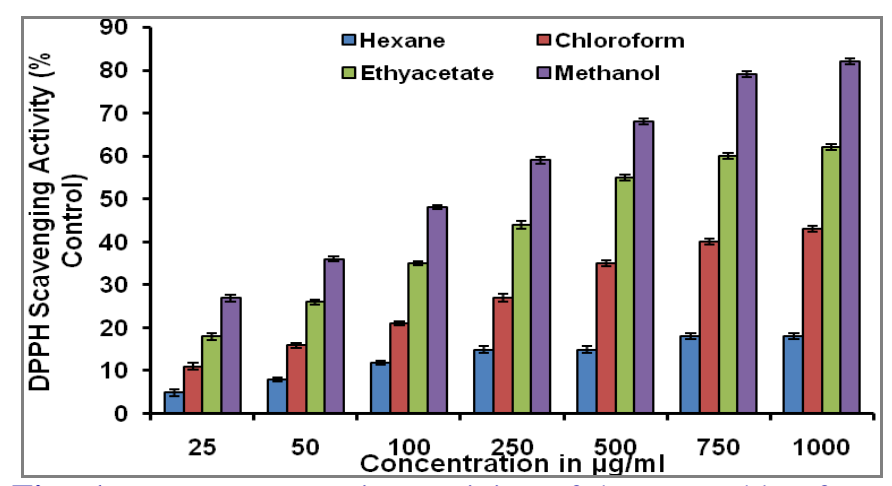

Fig. 1: DPPH scavenging activity of hexane, chloroform, ethylacetate and methanol extracts of leaves of Eclipta prostrata. Different concentrations i.e. 25, 50, 100, 250, 500, 750 and $1000 \mu \mathrm{g} / \mathrm{ml}$ was used to determine concentration dependent DPPH radical scavenging activity. DPPH radical scavenging activity was expressed in \% control. Each value represents mean $\pm \mathrm{SE}$ of three independent experiments. The values are significant at $p<0.05$.

The FRAP assay is a simple, convenient and reproducible method widely employed to determined the total antioxidant activity of biological samples (Pulido et al., 2000). As shown in the Fig. 2. methanol, ethyl acetate, chloroform and hexane leaf extracts of Eclipta prostrata exhibited $80.25,65.0,42.5$ and $15.75 \%$, of total antioxidant activity respectively, at $1 \mathrm{mg} / \mathrm{ml}$. The methanolic extracts of leaves of Eclipta prostrata showed the highest total antioxidant activity compared with other solvent extracts.

Super oxide is biologically important radical as it can form singlet oxygen and hydroxyl radical which can contributes to the pathogenesis of many diseases. Over production of super oxide anion radical contributes to redox imbalance and associated with harmful physiological consequences (Gulcin et al., 2005). 


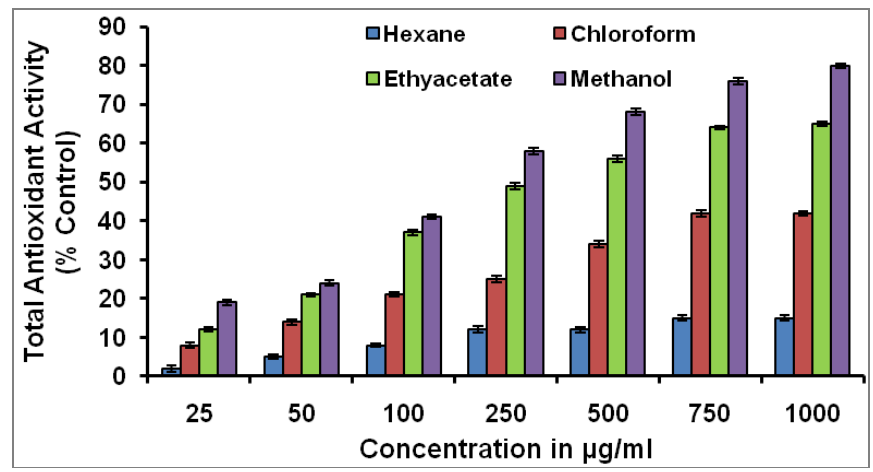

Fig. 2: Total antioxidant activity of hexane, chloroform, ethylacetate and methanol extracts of leaves of Eclipta prostrata. Each value represents mean \pm SE of three independent experiments. The values are significant at $p<0.05$.

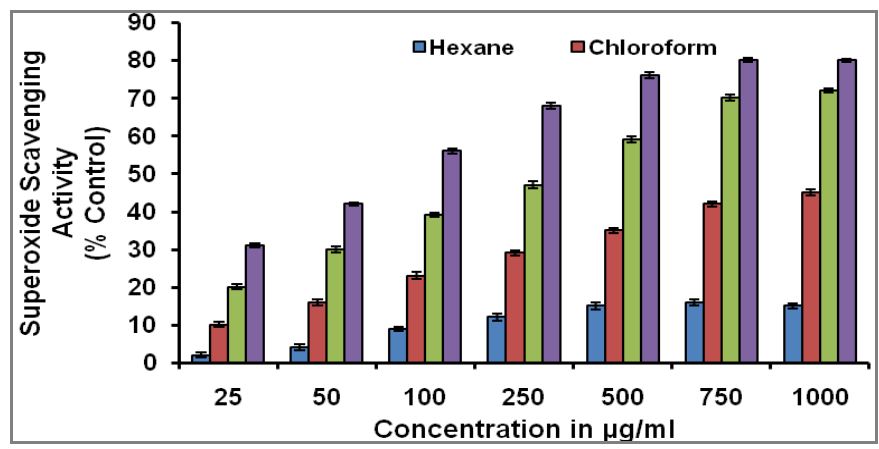

Fig. 3: Superoxide radical scavenging activity of hexane, chloroform, ethylacetate and methanol extracts of leaves of Eclipta prostrata. Each value is expressed as mean \pm standard deviation $(\mathrm{n}=3)$. Concentration $(\mu \mathrm{g} / \mathrm{ml})$ taken on $\mathrm{X}$-axis and $\%$ inhibition taken on $\mathrm{Y}$-axis.

Super oxide anions can be generated artificially from the hydroxylamine EDTA system. The scavenging ability of extracts can be assayed by NBT reduction method. The superoxide scavenging ability of the hexane, chloroform, ethyl acetate and methanol were found to be 80.50, 72.35, 45.20 and $15.65 \%$, respectively (Fig. 3). Among the four extracts methanolic extract possessed highest scavenging activity, whereas known antioxidant quercetin exhibited $85.45 \%$ at $1000 \mu \mathrm{g} / \mathrm{ml}$. The results showed that methanolic extract of leaves of Eclipta prostrata exhibited the highest superoxide radical scavenging activity on par with standard antioxidant BHT.

Hydroxyl radical is the most deleterious and reactive radical among the ROS with shortest half-life compared to other free radicals. Hydroxyl radicals derive from oxygen in presence of transition metal ion $\left(\mathrm{Fe}^{2+)}\right.$ and cause the degradation of deoxyribose into malondialdehyde which produces a pink chromogen with thiobarbituric acid (Halliwell et al., 1987). The chloroform and methanolic extract of leaves of Eclipta prostrata exhibited hydroxyl radical scavenging activity in a dose dependent manner and significant inhibition was observed at $1000 \mu \mathrm{g} / \mathrm{ml}$ concentration with 72.50 and 76.20 , respectively which is similar to the hydroxyl scavenging activity of natural antioxidant, quercetin 76.85\% used as standard (Fig. 4).

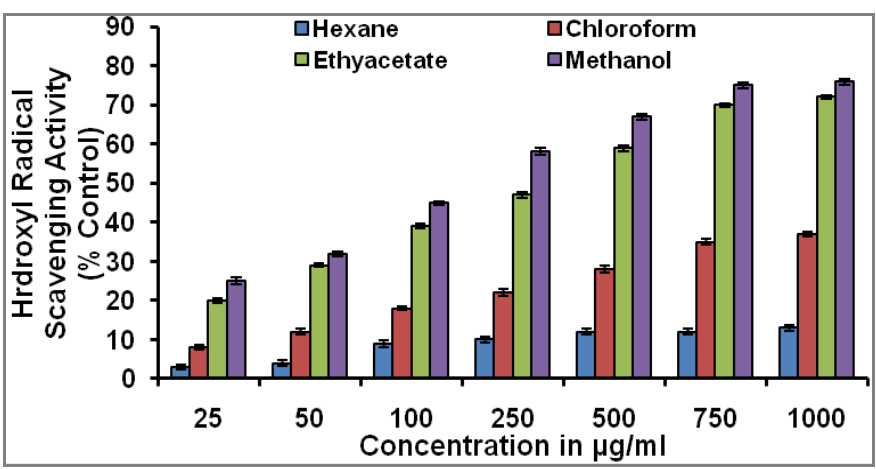

Fig. 4: Hydroxylradical scavenging activity of hexane, chloroform, ethylacetate and methanol extracts of leaves of Eclipta prostrata. Each value is expressed as mean \pm standard deviation $(\mathrm{n}=3)$. Concentration $(\mu \mathrm{g} / \mathrm{ml})$ taken on $\mathrm{X}$-axis and $\%$ inhibition taken on $\mathrm{Y}$-axis.

Preliminary phytochemical analysis of methanolic extract of leaves of Eclipta prostrata was carried out using specific qualitative tests to identify the active principle responsive for antioxidant activity. The results showed that the methanolic extract contained significant levels of flavonoids, moderate levels of polyphenolics and very low levels of alkaloids. The results also showed that tannins and saponins are absent in methanolic extract. Similarly ethylacetate extract possessed moderate levels of flavonoids and low levels of polyphenols. But other phyto-constituents such as tannins and saponins were not detected in methanolic and ethylacetate extracts and are present in hexane and chloroform extracts. From the results of phytochemical analysis of it was found that flavonoid and polyphenols content is more in methanolic extract of leaves of Eclipta prostrata.

Table 1. Phytochemical analysis of different solvent extracts of Eclipta prostrata leaves.

\begin{tabular}{lllll}
$\begin{array}{l}\text { Phytochemical } \\
\text { constituent }\end{array}$ & Hexane & Chloroform & Ethylacetate & Methanol \\
\hline Alkaloids & - & + & + & + \\
Polyphenols & - & + & ++ & ++ \\
Flavonoids & - & ++ & +++ & ++++ \\
Tannins & ++ & + & - & - \\
Saponins & + & + & - & - \\
\hline
\end{tabular}

Solvent extracts $(1000 \mu \mathrm{g} / \mathrm{ml})$ were analyzed to detect the presence of different phytochemicals using standard qualitative tests. Based on the colour intensity, the results were expressed as arbitrary units high $(++++)$, moderate $(+++)$, low $(++$ or +$)$, and absent $(-)$. 


\section{Conclusion}

Medicinal plants are good source of natural antioxidants. However, the nature and amount of antioxidant compounds extracted is varied from solvent to solvent. Different solvent extracts of the leaves of Eclipta prostrata i.e., hexane, ethyl acetate, chloroform and methanol were evaluated by using synthetic DPPH radical.

From the results of the present study, it is concluded that the methanolic extract of Eclipta prostrata leaves exhibited high antioxidant, free radical scavenging activities. The results also indicate that plant extract is a potential source of natural antioxidant, which might be helpful in mitigating the various oxidative stress mediated disorders. Further investigation on isolation of antioxidant compounds from methanolic plant extract is under progression.

\section{Conflict of interest statement}

Authors declare that they have no conflict of interest.

\section{References}

Beauchamp, C., Fridovich, I., 1971. Superoxide dismutase: Improved assay and an assay applicable to acrylamide gel. Anal. Biochem. 10, 276-287.

Chaudhary, S. R., Chavan, M. J., Gaud, R. S., 2004. Anti inflammatory and analgesic activity of Capparis zeylanica root extracts. Ind. J. Natural Prod. 20, 36-39.

Cuendet, M., Hostettmann, K., Potterat, O., 1997. Iridoid glucosides with free radical scavenging properties from Fragrea blumei. Helv. Chim. Acta. 80, 1144-1151.

Droge, W., 2005. Oxidative stress and ageing: Is ageing a cysteine deficiency syndrome? Phil. Trans. R. Soc. B. 360, 2355-2372.

Evans, P., Halliwell, B., 2001. Micronutrients: Oxidant/antioxidant status. Br. J. Nutr. 85, S67-74.

Farnsworth, N. R., Soejarto, D. D., 1991 .Global importance of medicinal plants. In: Conservation of Medicinal Plants (Eds.: Akerele, O., Heywood, V., Synge, H.). Cambridge University Press, Cambridge. pp.25-52.

Gulcin, I., Ahmet, H., Cesur, A. M., Determination of in vitro antioxidant and radical scavenging activities of propofol. Chem. Pharm. Bull. 53, 281-285.

Halliwell, B., Gutteridge, J. M. C., 1989. Free Radicals in Biology and Medicine. $3^{\text {rd }}$ Edn. Clarendon Press, Oxford.

Halliwell, B., Gutteridge, J. M., Aruoma, O. I., 1987. The deoxyribose method: A simple "test-tube" assay for determination of rate constants for reactions of hydroxyl radicals. Anal. Biochem. 15, 215-219.
Kobari, M., Yang, Z., Gong, D., Heissmeyer, V., Zhu, H., Jung, Y. K., Angelica, M., Gakidis, M., Rao, A., Sekine, T., Ikegami, F., Yuan, C., Yuan, J., 2004. Wedelolactone suppress LPS-induced caspase-11 expression by directly inhibiting the IKK complex. J. Cell Death Differ. 11(1), 123-130.

Latha, S., Daniel, M., 2001. Phenolic antioxidants of some common pulses. J. Food Sci. Technol. 38, 272-273.

Maxwell, S.R., 1995. Prospects for the use of antioxidant therapies. Drugs. 49, 345-361.

Mazid, M., Ahmed, K. T., Firoz, M., 2012. Medicinal plant of rural India: A review of use by Indian folks. Indo Global J. Pharm. Sci. 2(3), 286-304.

Md. Nur, A., Nusrat, J. B., Rafiquzzaman, Md., 2013. Review on in vivo and in vitro methods evaluation of antioxidant activity. Saudi Pharm. J. 21(2), 143-152.

Melo, P. A., Nascimento, M. C., Mors, W. B., Surez-Kurtz, G., 1994. Inhibition of the mytotoxic and hemorrhagic activities of crotalid venoms by Eclipta prostrata (Astraceae) extracts and constituents. Toxicon. 32, 595603.

Miller, D. M., Buettner, G. R., Aust, S. D., 1990. Transition metals's catalysts of "autoxidation" reactions. Free Radic. Biol. Med. 8, 95-108.

Nanjo, F., Goto, K., Seto, R., Suzuki, M., Sakai, M., Hara, Y., 1996. Scavenging effects of tea catechins and their derivatives on 1,1-diphenyl-2-picryl hydrazyl radical. Free Radic. Biol. Med. 21, 895-902.

Packer, L., Rimbach, G., Virgili, F., 1999. Antioxidant activity and biologic properties of a procyanidin-rich extract from pine (Pinus maritima) bark, pycnogenol. Free Radic. Biol. Med. 27, 704-724.

Pulido, R., Bravo, L., Saura-Calixto, F., 2000. Antioxidant activity of dietary polyphenols as determined by a modified ferric reducing/antioxidant power assay. J. Agric. Food Chem. 48, 3396-3402.

Ridnour, L. A., Isenberg, J. S., Espey, M. G., Thomas, D. D., Roberts, D. D., Wink, D. A., 2005. Nitric oxide regulates angiogenesis through a functional switch involving thrombospondin-1. Proc. Natl. Acad. Sci. 102, 1314713152.

Sazada, S., Verma, A., Rather, A. A., Jabeen, F., Meghvansi, M. K., 2009. Preliminary phytochemicals analysis of some important medicinal and aromatic plants. Adv. Biol. Res. 3(5-6), 188-195.

Vardar-Unlü, G., Candan, F., Sökmen, A., Daferera, D., Polissiou, M., Sökmen, M., Dönmez, E., Tepe, B., 2003. Antimicrobial and antioxidant activity of the essential oil and methanol extracts of Thymus pectinatus Fisch. Et. Mey. var. pectinatus (Lamiaceae). J. Agric. Food Chem. 51, 63-67.

Wagner, H., Geyer, B., Kiso, Y., Hikino, H., Roa, G.S., 1986, Coumestans as the main active principles of the liver drugs Eclipta alba and Wedelia calendulacea. Planta Med. 52, 370-374.

Wong, S. M., Antus, S., Gottengen, A., Fessler, B., Roa, G. 
S., Sonnenbichler, J., Wagner, H., 1988. Wedelolactone and coumestan derivatives as new antihepatotoxic and antiphlogestic principles. Arzneimittelforschung. 38(5), 661-665.
Wong, S.P., Lai, P.L., Jen, H.W.K., 2006. Antioxidant activities of aqueous extracts of selected plants. Food Chem. 99, 775-783.

\section{How to cite this article:}

Naveen Kumar, A. D., Rama Devi, M., Kasi Naidu, T., Mahesh Kumar, M.V.S., 32016. Antioxidant activities and phytochemical analysis of Eclipta prostrata. Int. J. Curr. Res. Biosci. Plant Biol. 3(8), 39-44.

doi: http://dx.doi.org/10.20546/ijcrbp.2016.308.006 